\title{
Minimally Invasive Versus Open Total Gastrectomy for Gastric Cancer: A Systematic Review and Meta-analysis of Short-Term Outcomes and Completeness of Resection
}

\author{
Surgical Techniques in Gastric Cancer
}

\author{
Jennifer Straatman ${ }^{1} \cdot$ Nicole van der Wielen ${ }^{1} \cdot$ Miguel A. Cuesta ${ }^{1} \cdot$ \\ Elly S. M. de Lange - de Klerk ${ }^{2} \cdot$ Elise P. Jansma ${ }^{3} \cdot$ Donald L. van der Peet ${ }^{1}$
}

Published online: 8 September 2015

(c) The Author(s) 2015. This article is published with open access at Springerlink.com

\begin{abstract}
Minimally invasive surgical techniques for gastric cancer are gaining more acceptance worldwide as an alternative to open resection. In order to assess the role of minimally invasive and open techniques in total gastrectomy for cancer, a systematic review and meta-analysis was performed. Articles comparing minimally invasive versus open total gastrectomy were reviewed, collected from the Medline, Embase, and Cochrane databases. Two different authors (JS and NW) independently selected and assessed the articles. Outcomes regarding operative results, postoperative recovery, morbidity, mortality, and oncological outcomes were analyzed. Statistical analysis portrayed the weighted mean difference (WMD) with a $95 \%$ confidence interval and odds ratio (OR). Out of 1242 papers, 12 studies were selected, including a total of 1360 patients, of which 592 underwent minimally invasive total gastrectomy (MITG). Compared to open total gastrectomy (OTG), MITG showed a longer operation time (WMD: $48.06 \mathrm{~min}, P<0.00001$ ), less operative blood loss (WMD: $-160.70 \mathrm{~mL}, P<0.00001$ ), faster postoperative recovery, measured as shorter time to first flatus (WMD -1.05 days, $P<0.00001$ ), shorter length of hospital stay (WMD: -2.43 days, $P=0.0002$ ), less postoperative complications (OR $0.66, P=0.02$ ), similar mortality rates (OR $0.60, P=0.52$ ), and similar rates in lymph node yield (WMD $-2.30, P=0.06$ ). Minimally invasive total gastrectomy showed faster postoperative recovery and less postoperative complications, whereas completeness of the resection was similar in both groups. Duration of surgery was longer in the minimally invasive group. Only comparative non-randomized studies were available, further emphasizing the need for a prospective randomized trial comparing MITG and OTG.
\end{abstract}

\section{Introduction}

Gastric cancer is responsible for ten per cent of all cancerrelated deaths worldwide, with the highest incidence rates in Eastern Asia, Eastern Europe, and South America [1].

Jennifer Straatman

je.straatman@vumc.nl

1 Department of Gastrointestinal Surgery, VU University Medical Centre, De Boelelaan 1117, ZH 7F020,

1081 HV Amsterdam, The Netherlands

2 Department of Epidemiology and Biostatistics, VU University Medical Centre, Amsterdam, The Netherlands

3 Medical Library, VU University Medical Centre, Amsterdam, The Netherlands
Until this day, the only curative treatment for gastric cancer is gastrectomy with adequate lymph node dissection [2]. As (neo)-adjuvant therapy has proven to be successful, an increasing number of patients are treated this way $[3,4]$. In recent years, minimally invasive techniques have gained increasing interest in the treatment of gastric cancer. The first reported minimally invasive distal gastrectomy was performed in 1994 by Kitano et al. [5], followed in 1996 by the first minimally invasive total gastrectomy for cancer by Azagra et al. [6]. Since then, several studies, and metaanalyses examined the safety and feasibility of minimally invasive gastrectomy for cancer [7-9]. The outcomes of these studies have shown promising results such as faster recovery, less pain, shorter hospital stay, improved quality of life after surgery, and above all equal outcomes of 
morbidity and mortality in comparison with open gastrectomy [10]. Although the results are promising, the number of studies was relatively small, their power was low, and no difference was made between types of gastrectomy, but mainly focused on distal gastrectomy or combined the different types of gastrectomies, partial, total and/or proximal [9-11]. Consequently, a heterogeneous study population was created, and as a result, outcomes are not transferable to an actual group of total gastrectomy patients [7, 12, 13].

The aim of this study is to assess evidence for a minimally invasive approach in total gastrectomy by comparing MITG to OTG with respect to operative data, conversion rate, postoperative data, morbidity and mortality, completeness of surgical resection, postoperative recovery, and long-term outcomes.

\section{Materials and methods}

\section{Literature search}

To identify all relevant publications, a systematic search in the bibliographic databases PubMed, EMBASE, and The Cochrane Library (via Wiley) from inception to February 5th 2015 was performed. Search terms included controlled terms from MeSH in PubMed, EMtree in EMBASE.com as well as free text terms. Free text terms were only used in The Cochrane library. Search terms expressing 'stomach neoplasms' were used in combination with search terms comprising 'open surgery' and 'laparoscopy.' The reference list of included articles was hand-searched for relevant publications.

\section{Selection criteria}

Two authors (J.S. and N.W.) independently evaluated the search findings for potential eligibility for this meta-analysis using the Medline, Embase, and Cochrane databases. The inclusion criteria were as follows: (1.) Article published in English language; (2.) Only full-text articles, no abstracts, or case reports were included; and (3.) The study had to compare minimally invasive total gastrectomy (MITG) with open total gastrectomy (OTG) for cancer.

\section{Definitions}

Operation duration was defined in minutes, and blood loss in milliliters. All studies reporting blood loss in grams were not included in the analysis of this parameter. Hospital stay and time to first flatus were reported in days. If studies reported, these parameters in hours a conversion to days would be made. Definitions of complications varied between different studies, and there was no consensus in reporting type or grade of complication such as the Clavien-Dindo grading system for the classification of surgical complications [14, 15]. Therefore, only the number of complications was reported. In-hospital mortality was defined as mortality within 30 days after surgery. Lymph node yield was measured as the mean number of resected lymph nodes with a standard deviation. Data regarding mean resection margins were also collected along with survival data. None of the studies reported neo-adjuvant treatment.

\section{Data extraction and quality assessment}

The reviewers (J.S. and N.W.) extracted the following data from each study: first author, title of the article, year of publication, geographical region, type of study, type of gastrectomy, type of reconstruction, TNM stage, number of patients included, number of patients who underwent open gastrectomy, number of patients who underwent minimally invasive gastrectomy, operation duration, estimated blood loss, time to first flatus, time to first oral intake, length of hospital stay, percentage of postoperative complications, and percentage of mortality. Moreover, data concerning follow-up and survival were collected. All the data were reported in means and standard deviation. If the article did not report the parameters in means and standard deviations, a request for this information was sent to the concerning author and this information was received from one author [16]. Due to the difficulty of receiving raw data, the data from the published articles were used in this meta-analysis. To assess the quality of the studies, all reviewers classified the studies using the Newcastle-Ottawa Quality Assessment Scale (NOS) for retrospective cohort studies and case-control studies [17]. A maximum of nine points could be awarded, four points for selection criteria, two points for comparability, and three points for outcome. Beforehand, the criteria were discussed between the reviewers so an equal scoring method was used. In case of doubt, deliberation was conducted between the reviewers and the problem would be resolved with mutual approval. Studies achieving six or more points would be classified as high quality and were used for further analysis. Moreover, the level of evidence was assessed for each study [18].

\section{Statistical analysis}

The meta-analysis was performed in line with the recommendations from the PRISMA Statement for Reporting Systematic Reviews and Meta-Analyses [19]. Review Manager version 5.3.3 (2014) was used for data analyses, as downloaded from the Cochrane Library. Continuous 


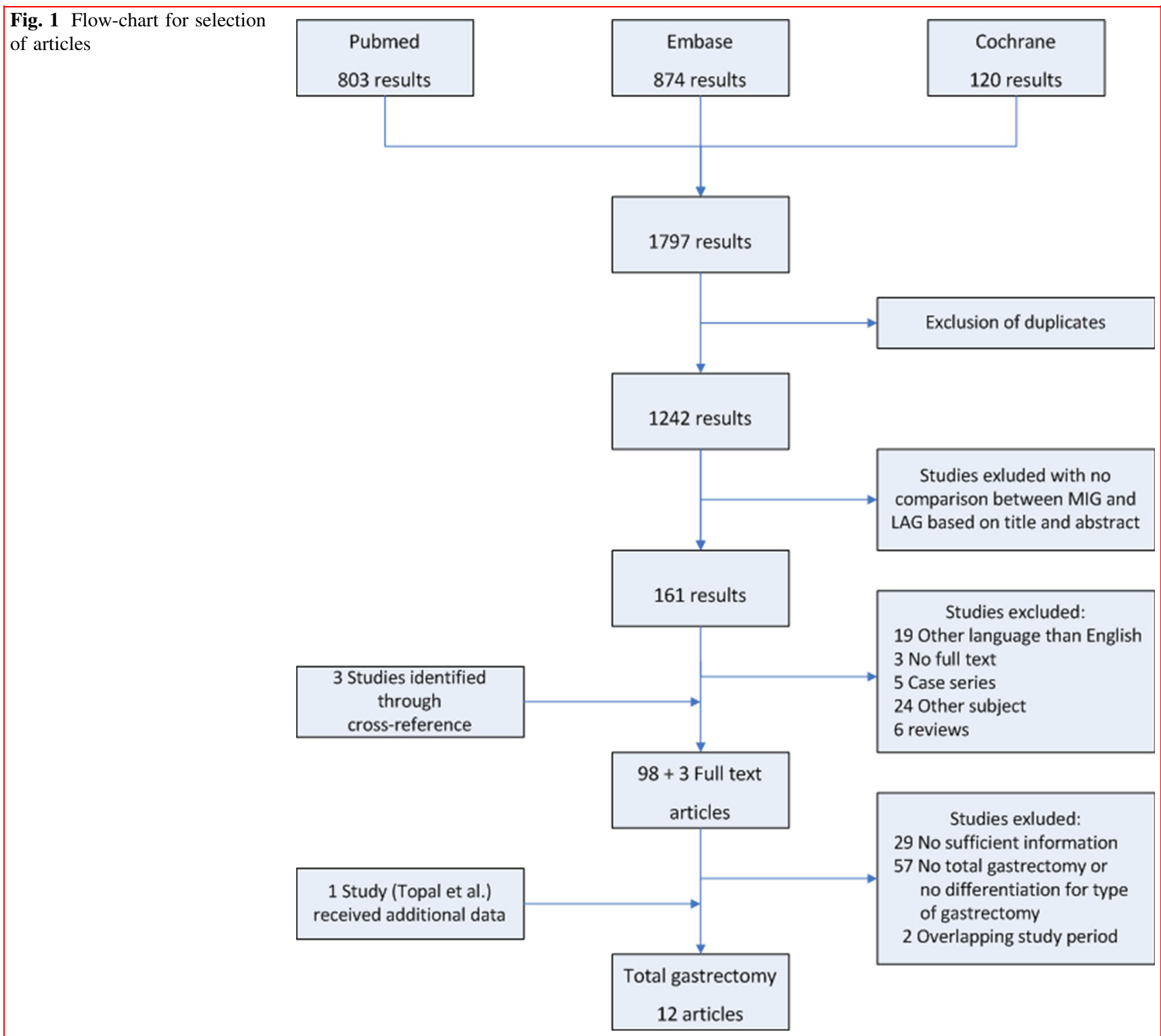

variables were assessed using the weighted mean difference. Dichotomous variables were assessed using the Odds Ratio. To account for clinical heterogeneity, the random effects model based on DerSimonian and Laird's method was used. $P$ value $<0.05$ was considered statistically significant.

\section{Results}

\section{Study selection}

The literature search resulted in 1797 hits; after deleting the duplicate articles, 1242 articles remained; Articles were independently screened based on title and abstract by two different authors (J.S. and N.W.) and a selection of 153 articles for full-text analysis remained. Fifty-seven articles did not meet the pre-defined criteria after reading the fulltext. Via cross-referencing, an additional three articles were added, thus resulting in 99 full-text articles regarding laparoscopic versus open gastrectomy. The focus of this meta-analysis was to analyze all studies regarding total gastrectomy; therefore, we only included articles comparing minimally invasive total gastrectomy with open total gastrectomy. When the same author published more than one study from an overlapping study period, the article with the longest study period or largest cohort was included in the analysis. This eventually resulted in twelve relevant articles. A flow-chart of article selection is depicted in Fig. 1. 


\section{Study characteristics}

A total of ten retrospective cohort studies and two casecontrol study were identified as suitable for analysis [16, 20-30]. The total number of patients included in these studies was 1360 , with $592(43.5 \%)$ patients who underwent MITG and 768 (56.5\%) who underwent OTG. Five studies reported that none of the minimally invasive procedures were converted to an open procedure; Lee et al. reported four patients to be converted from minimally invasive surgery to open surgery. However, these patients were excluded from the study; other studies did not report information regarding conversion rates $[20,21,25,27,28$, 30]. Nine out of 12 studies were conducted in Asian countries (Japan, Korea and China) and three studies were conducted in European countries (France, Italy and Belgium). An overview of the included articles is depicted in Table 1. Analysis of tumor stage according to TNM stage or tumor size showed a significant difference in two studies $[25,26]$. Both studies reported a greater tumor size in the open group.

Baseline characteristics were comparable in eleven studies. Topal et al. reported in the article that baseline characteristics were comparable; however, there was no further information regarding these characteristics [16]. Thus, this study received one point for comparability due to imprecise results. Other studies received only one point due to the fact that the study did not correct for oncological stage, which the researchers deemed to be an important factor. An overview of attributed scores is portrayed in Table 2.

\section{Operative results}

All studies described the mean operative time. The procedure was found to be significantly longer for the MITG approach in all studies. The weighted mean difference was $48.06 \mathrm{~min}$ (95\% CI $\quad 30.75-65.38)$ and $P<0.00001$ (Fig. 2).

Ten out of twelve studies described estimated blood loss. In all ten studies, blood loss was significantly less in the MITG group. The weighted mean difference was $-160.70 \mathrm{~mL} \quad(95 \% \quad \mathrm{CI} \quad-224.27$ to -97.12 and $P<0.00001$ ) (Fig. 2).

\section{Postoperative recovery}

Nine studies described the time to first flatus. The time to first flatus was significantly shorter in the MITG group. All studies showed a shorter time period to first flatus in the minimally invasive group. The weighted mean difference was -1.05 days $(95 \% \quad \mathrm{CI}-1.44$ to -0.66$)$ and $P<0.00001$ (Fig. 3).

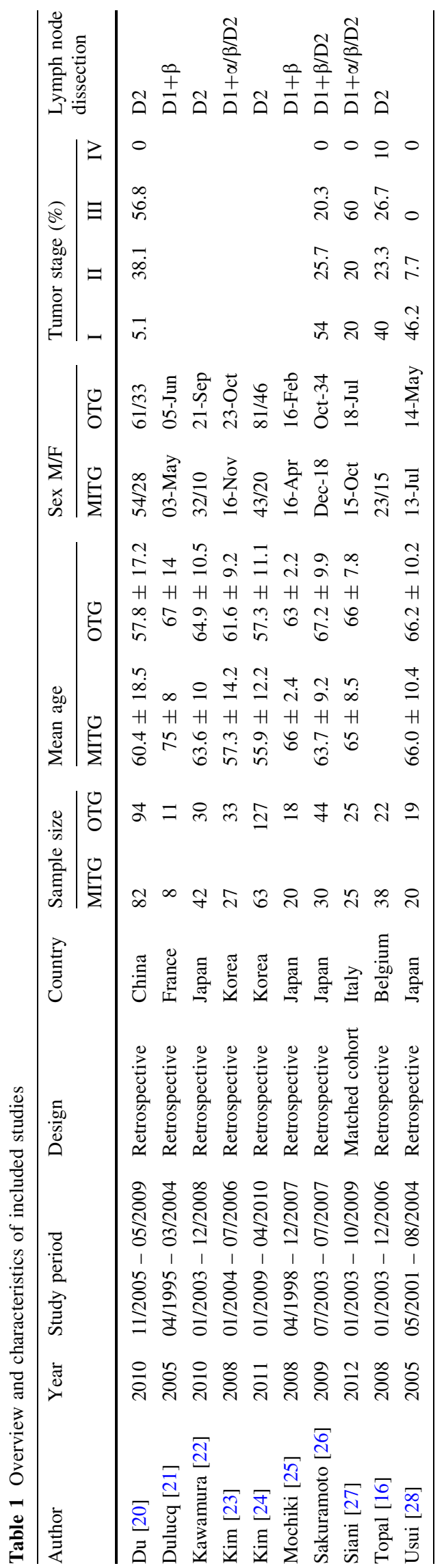




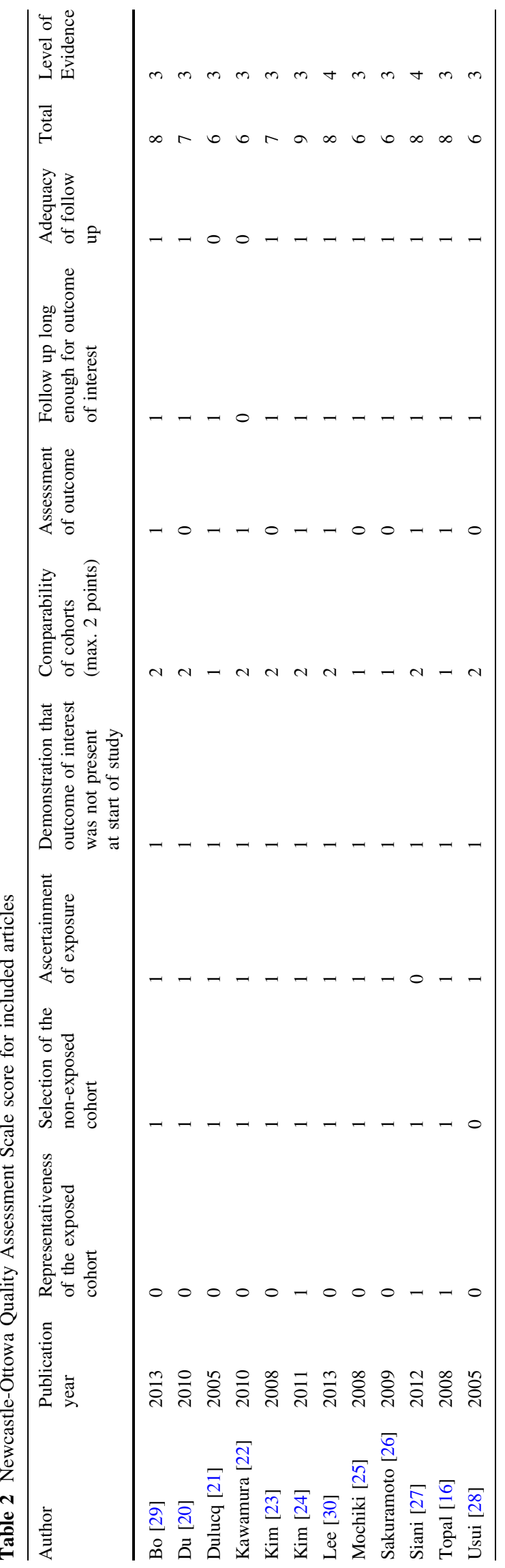

Ten out of twelve studies described the length of hospital stay. The duration of hospitalization was significantly shorter in the MITG group. Two studies showed a mean shorter hospital stay in the OTG group in comparison with the MITG group [16, 28]. The weighted mean difference was -2.43 days $(95 \%$ CI -3.71 to -1.16$)$ and $P=0.0002$ (Fig. 3).

\section{Morbidity and mortality}

Ten studies report results of postoperative complications. There were significantly less postoperative complications in the group who underwent MITG. The odds ratio was 0.66 (95\% CI $0.47-0.93$ ) and $P<0.02$ (Fig. 4). No differentiation in type of complications was listed in the included articles. Long-term follow-up data regarding complications were not available in these studies.

Eight out of twelve studies stated 30-day mortality rates, with four studies describing no mortality in both groups $[26,27,29,30]$. Two other studies [23, 24] did not report mortality rates but did report postoperative complications. There was no significant difference in mortality rates between the MITG group and the OTG group. The odds ratio was 0.60 (95\% CI $0.13-2.82$ ) and $P=0.52$ (Fig. 4).

\section{Long-term survival}

Long-term survival was reported in eight studies, ranging from 2 to 180 months follow-up. No differences in survival were reported between MITG and OTG in four studies that analyzed survival $[25,27,29,30]$. The other articles only described survival data. Due to differences in follow-up length, differences in analysis of survival, heterogeneity between studies, and dispersion in follow-up data, pooled analysis of survival data was not possible.

\section{Completeness of oncological resection}

Eleven out of twelve studies described the total number of resected lymph nodes. There was no significant difference between the two groups. The weighted mean difference was -2.30 (95\% CI -4.73 to 0.14 ) and $P=0.06$ (Fig. 5). Eight studies showed a higher mean number of resected lymph nodes in favor of the open group. None of the articles provided information on the resected stations and whether this is in accordance with a D1, D1+, or D2 lymphadenectomy.

Only three studies provided details regarding the extent of distal and proximal resection margins. No significant differences were observed in the resection margin between the groups [20, 24, 29]. Additionally, three studies reported results of resection radicality, of which two studies reported R0 resections in all patients [20, 21]. One study 


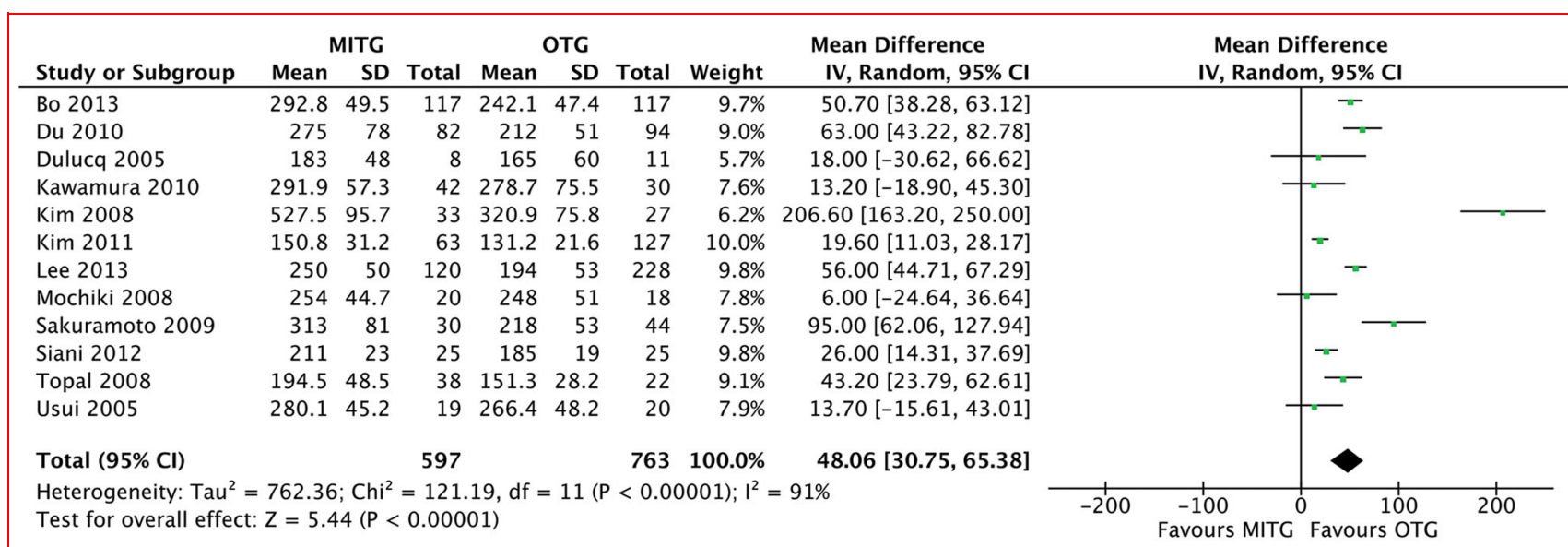

\section{Operative time}

\begin{tabular}{|c|c|c|c|c|c|c|c|c|c|c|}
\hline \multirow[b]{2}{*}{ Study or Subgroup } & \multicolumn{3}{|c|}{ MITG } & \multicolumn{3}{|c|}{ OTG } & \multicolumn{2}{|r|}{ Mean Difference } & \multirow{2}{*}{\multicolumn{2}{|c|}{$\begin{array}{c}\text { Mean Difference } \\
\text { IV, Random, } 95 \% \mathrm{Cl}\end{array}$}} \\
\hline & Mean & SD & Total & Mean & SD & Total & Weight & IV, Random, $95 \% \mathrm{CI}$ & & \\
\hline Bo 2013 & 196.9 & 88.4 & 117 & 358.2 & 158.7 & 117 & $11.5 \%$ & $-161.30[-194.22,-128.38]$ & 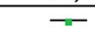 & \\
\hline Du 2010 & 156 & 112 & 82 & 339 & 162 & 94 & $11.4 \%$ & $-183.00[-223.74,-142.26]$ & - & \\
\hline Dulucq 2005 & 81 & 107 & 8 & 125 & 95 & 11 & $9.5 \%$ & $-44.00[-137.00,49.00]$ & & \\
\hline Kawamura 2010 & 53.6 & 42.6 & 42 & 303.9 & 217.3 & 30 & $10.1 \%$ & $-250.30[-329.12,-171.48]$ & & \\
\hline Kim 2011 & 179.7 & 123.8 & 63 & 272.7 & 209.6 & 127 & $11.2 \%$ & $-93.00[-140.58,-45.42]$ & & \\
\hline Lee 2013 & 215 & 188 & 120 & 194 & 165 & 228 & $11.4 \%$ & $21.00[-18.88,60.88]$ & & \\
\hline Sakuramoto 2009 & 134 & 98 & 30 & 407 & 270 & 44 & $9.7 \%$ & $-273.00[-360.15,-185.85]$ & & \\
\hline Siani 2012 & 250 & 150 & 25 & 495 & 190 & 25 & $9.4 \%$ & $-245.00[-339.89,-150.11]$ & & \\
\hline Topal 2008 & 44.2 & 91.1 & 38 & 330.5 & 384.9 & 22 & $6.7 \%$ & $-286.30[-449.72,-122.88]$ & & \\
\hline Usui 2005 & 227.5 & 148.1 & 19 & 393.1 & 173.6 & 20 & $9.2 \%$ & $-165.60[-266.71,-64.49]$ & & \\
\hline Total $(95 \% \mathrm{Cl})$ & & & 544 & & & 718 & $100.0 \%$ & $-160.70[-224.27,-97.12]$ & & \\
\hline $\begin{array}{l}\text { Heterogeneity: } \mathrm{Tau}^{2} \\
\text { Test for overall effect }\end{array}$ & $\begin{array}{l}8830.2 \\
Z=4.9\end{array}$ & $\begin{array}{l}4 ; \mathrm{Chi}^{2} \\
5(\mathrm{P}<\end{array}$ & $\begin{array}{r}=99.5 \\
.0000\end{array}$ & $9, \mathrm{df}=$ & $9(P<0$ & .00001 & $; 1^{2}=91$ & & $\begin{array}{l}-200- \\
\text { Favours }\end{array}$ & $\begin{array}{lrc} & 1 & 1 \\
0 & 100 & 200 \\
\text { Favours } & \text { OTG }\end{array}$ \\
\hline
\end{tabular}

\section{Blood loss}

Fig. 2 Forrest plot of comparison of operative data duration of operation (minutes) and peri-operative blood loss (ml)

reported two $\mathrm{R} 1$ resections, one in the open group and one in the minimally invasive group; all other patients had R0 resections [16]. Thus, no significant difference was found regarding radicality of the resection in both groups.

\section{Discussion}

The here presented meta-analysis aimed to assess the optimal surgical technique in patients undergoing total gastrectomy for cancer. The minimally invasive technique was compared to the open approach. Based on these findings, MITG was associated with less blood loss, a faster postoperative recovery, and less postoperative morbidity with similar mortality rates compared to OTG. Moreover, completeness of oncological resection concerning the number of lymph nodes resected was similar in both groups indicating that minimally invasive total gastrectomy seems to be non-inferior to open total gastrectomy in short-term outcomes. No conclusions could be made concerning longterm survival due to dispersion and inaccuracy of the disposable data.
All studies included were non-randomized and retrospective of nature. Although the observational nature might introduce bias, a meta-analysis of observational studies was deemed feasible [31]. No differences in baseline characteristics were observed in the included studies. All studies included all different stages of disease. Only two studies showed a significant difference in tumor size, where the tumor was greater in the open group [25, 26]. Most studies were conducted in Asian countries.

With exception of operative time, data concerning operative blood loss and recovery of the patient are in favor of the MITG group, indicating the reduced invasiveness of the procedure. Increased experience with this type of approach showed a clear decrease in operating time [32, 33].

This systematic review and meta-analysis assesses the optimal surgical strategy for total gastrectomy in patients with gastric cancer. Other systematic reviews and metaanalyses included both total and subtotal gastrectomy or regarded only laparoscopy-assisted techniques [9, 10].

Concerning the hospital stay, it should be noted that one article reported all patients were routinely discharged at 


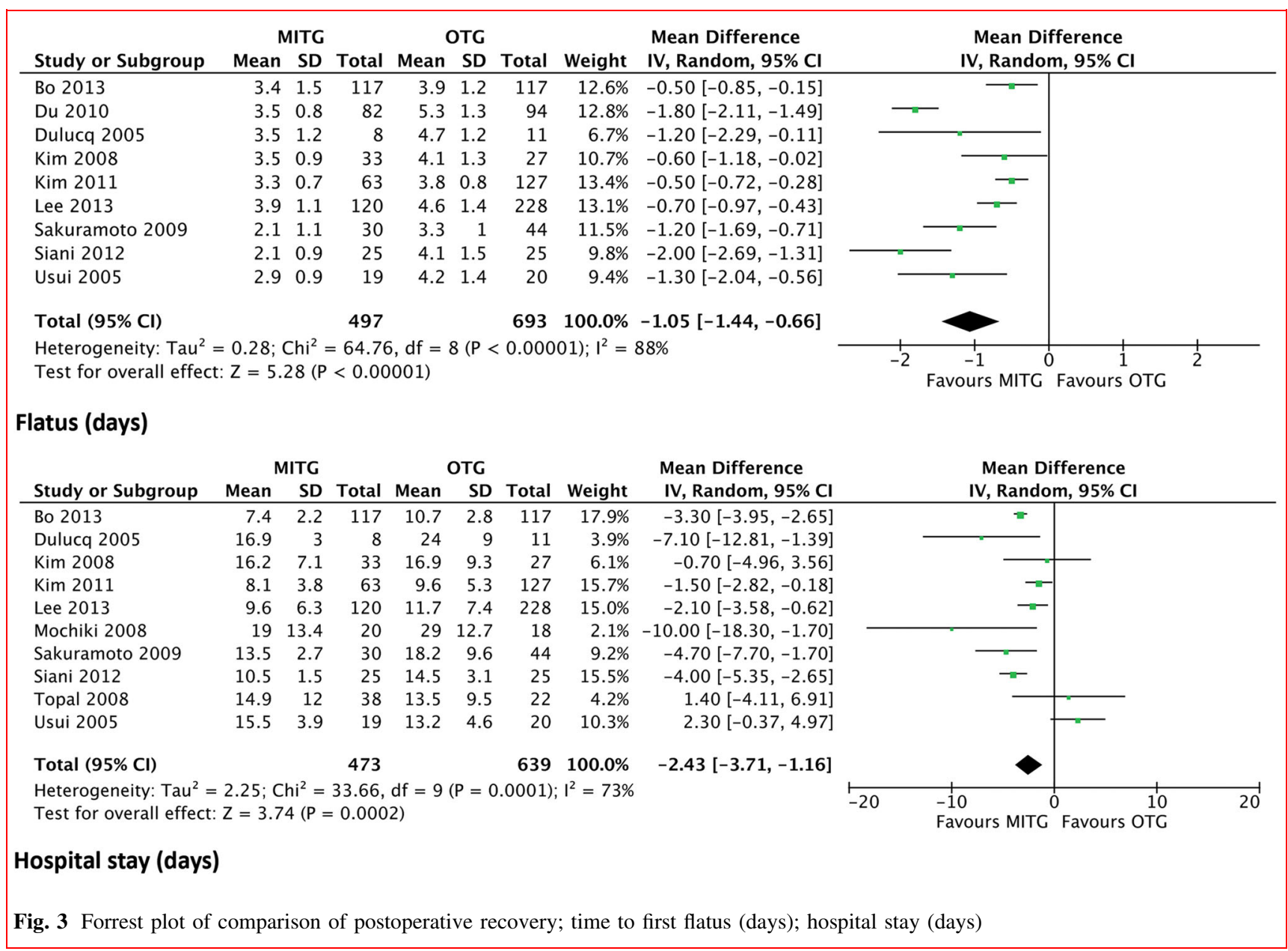

postoperative day 14 [22]. This study was not included for analysis of length of hospital stay. Another study stated the final decision for discharge was left to the patient's own decision [24]. No definitions of discharge criteria were provided in the other included studies. Therefore, no assurance can be made for the quality of this outcome.

Along with a faster postoperative recovery, postoperative complications were less prevalent in patients who underwent MITG. Complications were not reported using the Clavien-Dindo classification. Therefore, the grade of complications, minor or major, could not be taken into account in this meta-analysis. Also information on surgical and non-surgical complications was not provided. Moreover, no results of long-term complications or quality of life after surgery were described. Further research is necessary in order to assess the effect of minimally invasive techniques on Patient Reported Outcome Measurements such as quality of life and costeffectiveness.

30-day mortality showed no significant differences. Data for 30-day mortality were available from eight studies. The question remains if mortality did not occur in the other study groups, if it happened past postoperative day 30 , or if it was not measured at all.

The number of resected lymph nodes is considered a marker for radicality, survival, and quality of care [34-36]. A novel surgical technique should be non-inferior with regard to total lymph node resection and the distribution in stations. The here presented meta-analysis showed no significant difference in lymph node yield between MITG and OTG. There is no adequate reference to their distribution according to the Japanese classification [37]. Also information on the number of patients that received routine splenectomy was not available.

The results of the resection margin were only mentioned in three studies [20, 24, 29]. Of even greater interest is the long-term survival after both approaches with regard to survival and disease-free survival. In this meta-analysis, the analysis of long-term outcomes was not possible due to the lack of available data, heterogeneity between studies and dispersion in follow-up data. Therefore, no comparison could be made regarding this outcome. 


\begin{tabular}{|c|c|c|c|c|c|c|c|c|c|c|}
\hline Study or Subgroup & \multicolumn{2}{|c|}{ MITG } & \multicolumn{2}{|c|}{ OTG } & Weight & $\begin{array}{c}\text { Odds Ratio } \\
\mathrm{M}-\mathrm{H}, \text { Random, } 95 \% \mathrm{Cl}\end{array}$ & \multicolumn{3}{|c|}{$\begin{array}{c}\text { Odds Ratio } \\
\mathrm{M}-\mathrm{H}, \text { Random, } 95 \% \mathrm{Cl}\end{array}$} & \\
\hline Bo 2013 & 13 & 117 & 19 & 117 & $16.6 \%$ & $6 \quad 0.64[0.30,1.38]$ & & & & \\
\hline Du 2010 & 8 & 82 & 23 & 94 & $13.2 \%$ & $0.33[0.14,0.79]$ & & & & \\
\hline Dulucq 2005 & 0 & 8 & 2 & 11 & $1.1 \%$ & $0.22[0.01,5.34]$ & & & & \\
\hline Kim 2008 & 2 & 33 & 8 & 27 & $4.1 \%$ & $0.15[0.03,0.80]$ & & & & \\
\hline Kim 2011 & 8 & 63 & 24 & 127 & $13.3 \%$ & $0.62[0.26,1.48]$ & & & E & \\
\hline Lee 2013 & 22 & 120 & 37 & 228 & $24.9 \%$ & $1.16[0.65,2.07]$ & & & $f=$ & \\
\hline Mochiki 2008 & 4 & 20 & 4 & 18 & $4.6 \%$ & $0.88[0.18,4.17]$ & & & & \\
\hline Sakuramoto 2009 & 5 & 30 & 12 & 44 & $7.8 \%$ & $0.53[0.17,1.71]$ & & & - & \\
\hline Siani 2012 & 4 & 25 & 5 & 25 & $5.2 \%$ & $0.76[0.18,3.25]$ & & & & \\
\hline Topal 2008 & 15 & 38 & 9 & 22 & $9.2 \%$ & $0.94[0.32,2.75]$ & & & & \\
\hline Total $(95 \% \mathrm{Cl})$ & & 536 & & 713 & $100.0 \%$ & $0.66[0.47,0.93]$ & & & & \\
\hline Total events & 81 & & 143 & & & & & & & \\
\hline $\begin{array}{l}\text { Heterogeneity: } \mathrm{Tau}^{2}= \\
\text { Test for overall effect }\end{array}$ & $\begin{array}{l}=0.03 ; \mathrm{Ch} \\
: \mathrm{Z}=2.36\end{array}$ & $\begin{array}{l}\mathrm{hi}^{2}=10 \\
6(\mathrm{P}=0\end{array}$ & $\begin{array}{l}0.15, \mathrm{df}= \\
0.02)\end{array}$ & $=9(P=$ & $=0.34) ; I^{2}$ & ${ }^{2}=11 \%$ & 0.01 & $\begin{array}{c}0.1 \\
\text { Favours MITG }\end{array}$ & 1 Favours 10 & 100 \\
\hline \multicolumn{11}{|c|}{ Postoperative complications } \\
\hline Study or Subgroup & $\begin{array}{c}\text { MITC } \\
\text { Events }\end{array}$ & G Total & $\begin{array}{l}\text { OTC } \\
\text { Events }\end{array}$ & G Total & Weight & $\begin{array}{c}\text { Odds Ratio } \\
\text { M-H, Random, } 95 \% \mathrm{Cl}\end{array}$ & & $\begin{array}{r}\text { Odds } \\
M-H, \text { Rando }\end{array}$ & $\begin{array}{l}\text { Ratio } \\
\text { lom, } 95 \% \mathrm{Cl}\end{array}$ & \\
\hline Bo 2013 & 0 & 117 & 0 & 117 & & Not estimable & & & & \\
\hline Du 2010 & 0 & 82 & 2 & 94 & $25.8 \%$ & $0.22[0.01,4.74]$ & & -7 & & \\
\hline Dulucq 2005 & 0 & 8 & 1 & 11 & $21.7 \%$ & $0.41[0.01,11.46]$ & & & & \\
\hline Lee 2013 & 0 & 120 & 0 & 228 & & Not estimable & & & & \\
\hline Mochiki 2008 & 1 & 20 & 0 & 18 & $22.5 \%$ & $2.85[0.11,74.38]$ & & & 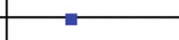 & \\
\hline Sakuramoto 2009 & 0 & 30 & 0 & 44 & & Not estimable & & & & \\
\hline Siani 2012 & 0 & 25 & 0 & 25 & & Not estimable & & & & \\
\hline Topal 2008 & 1 & 38 & 1 & 22 & $30.1 \%$ & $0.57[0.03,9.55]$ & & & & \\
\hline Total $(95 \% \mathrm{Cl})$ & & 440 & & 559 & $100.0 \%$ & $0.60[0.13,2.82]$ & & & & \\
\hline Total events & 2 & & 4 & & & & & & & \\
\hline $\begin{array}{l}\text { Heterogeneity: } \mathrm{Tau}^{2} \\
\text { Test for overall effect }\end{array}$ & $\begin{array}{l}=0.00 ; C h \\
: Z=0.65\end{array}$ & $\begin{array}{l}\mathrm{hi}^{2}=1 . \\
5(\mathrm{P}=0\end{array}$ & $\begin{array}{l}.33, \mathrm{df}= \\
0.52)\end{array}$ & $3(P=$ & $0.72) ; 1^{2}=$ & $=0 \%$ & 0.01 & 0.1 Favours MITG & 1 Favours OTG & 100 \\
\hline 30-day mortality & & & & & & & & & & \\
\hline
\end{tabular}

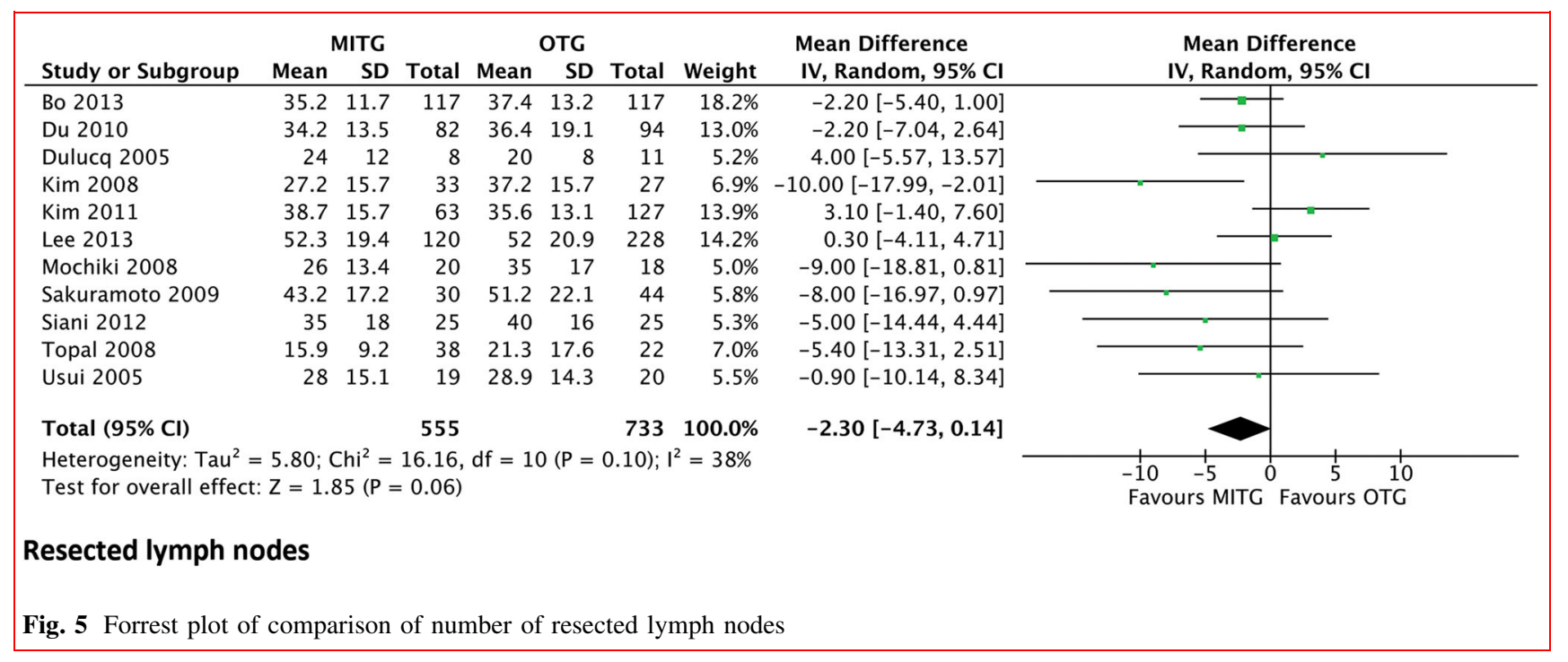




\section{Conclusion}

With similar results in lymph node yield, faster postoperative recovery, and less complications, the assumption may be made that minimally invasive gastrectomy is non-inferior to the open technique with regard to long-term recovery and completeness of the resection. However, resection margins and long-term survival data need to be evaluated. All included studies were non-randomized and retrospective of nature, which influences the quality of the depicted outcomes. A prospective randomized trial is indicated in order to establish the optimal surgical strategy in total gastrectomy for patients with gastric cancer and is currently underway from our department.

The primary outcome will be quality of oncological resection, as measured by the number of nodes according to the Japanese classification of gastric carcinoma, stating that minimally invasive techniques should be non-inferior. Lymph node stations are marked and analyzed separately according to the Japanese gastric cancer treatment guidelines [2]. Secondary outcomes will be postoperative recovery, hospital stay, morbidity and mortality, progression-free survival, overall survival, and quality of life [38].

\section{Compliance with ethical standards}

Conflict of interest Jennifer Straatman, Nicole van der Wielen, Miguel A. Cuesta, Elly S.M. de Lange - de Klerk, Ilse E.P. Jansma, and Donald L. van der Peet have nothing to disclose.

Open Access This article is distributed under the terms of the Creative Commons Attribution 4.0 International License (http://crea tivecommons.org/licenses/by/4.0/), which permits unrestricted use, distribution, and reproduction in any medium, provided you give appropriate credit to the original author(s) and the source, provide a link to the Creative Commons license, and indicate if changes were made.

\section{References}

1. Jemal A, Bray F, Center MM et al (2011) Global cancer statistics. CA Cancer J Clin 61:69-90

2. Japanese Gastric Cancer Association (2011) Japanese gastric cancer treatment guidelines 2010 (version 3). Gastric Cancer $14: 113-123$

3. Cunningham D, Allum WH, Stenning SP et al (2006) Perioperative chemotherapy versus surgery alone for resectable gastroesophageal cancer. N Engl J Med 355:11-20

4. Dikken JL, van Sandick JW, Maurits Swellengrebel HA et al (2011) Neo-adjuvant chemotherapy followed by surgery and chemotherapy or by surgery and chemoradiotherapy for patients with resectable gastric cancer (CRITICS). BMC Cancer 11:1-8

5. Kitano S, Iso Y, Moriyama M et al (1994) Laparoscopy-assisted Billroth I gastrectomy. Surg Laparosc Endosc 4:146-148

6. Azagra JS, Goergen M, De Simone P et al (1999) Minimally invasive surgery for gastric cancer. Surg Endosc 13:351-357
7. Cai J, Wei D, Gao CF et al (2011) A prospective randomized study comparing open versus laparoscopy-assisted D2 radical gastrectomy in advanced gastric cancer. Dig Surg 28:331-337

8. Lee JH, Son SY, Lee CM et al (2012) Morbidity and mortality after laparoscopic gastrectomy for advanced gastric cancer: results of a phase II clinical trial. Surg Endosc 27:2877-2885

9. Haverkamp L, Weijs TJ, van der Sluis PC et al (2013) Laparoscopic total gastrectomy versus open total gastrectomy for cancer: a systematic review and meta-analysis. Surg Endosc 27:1509-1520

10. Chen K, Xu XW, Mou YP et al (2013) Systematic review and meta-analysis of laparoscopic and open gastrectomy for advanced gastric cancer. World J Surg Oncol 11:1-13. doi:10.1186/14777819-11-182

11. Martinez-Ramos D, Miralles-Tena JM, Cuesta MA et al (2011) Laparoscopy versus open surgery for advanced and resectable gastric cancer: a meta-analysis. Rev Esp Enferm Dig 103:133-141

12. Kim KH, Kim MC, Jung GJ et al (2012) Comparative analysis of five-year survival results of laparoscopy-assisted gastrectomy versus open gastrectomy for advanced gastric cancer: a casecontrol study using a propensity score method. Dig Surg 29:165-171

13. Inokuchi M, Kojima K, Kato K et al (2013) Feasibility of laparoscopy-assisted gastrectomy for patients with chronic obstructive pulmonary disease. Surg Endosc 27:2102-2109

14. Clavien PA, Barkun J, de Oliveira ML et al (2009) The ClavienDindo classification of surgical complications; five year experience. Ann Surg 250:187-196

15. Dindo D, Demartines N, Clavien PA (2004) Classification of surgical complications; a new proposal with evaluation in a cohort of 6336 patient and results of a survey. Ann Surg 240:205-213

16. Topal B, Leys E, Ectors C et al (2008) Determinants of complications and adequacy of surgical resection in laparoscopic versus open total gastrectomy for adenocarcinoma. Surg End 22:980-984

17. Deeks JJ, Dinnes J, D'Amico R et al (2003) Evaluating nonrandomised intervention studies. Health Technol Assess 7:1-173

18. Centre for Evidence-Based Medicine. levels of evidence [CEBM web site]. Available at: http://www.cebm.net/?o=1025. accessed July 282014

19. Liberati A, Altman DG, Tetzlaff J et al (2009) The PRISMA statement for reporting systematic reviews and meta-analyses of studies that evaluate healthcare interventions: explanation and elaboration. BMJ 339:b2700

20. Du J, Zheng J, Li Y et al (2010) Laparoscopy-assisted total gastrectomy with extended lymph node resection for advanced gastric cancer-reports of 82 cases. Hepatogastroenterology 57:1589-1594

21. Dulucq JL, Wintringer P, Stabilini C et al (2005) Laparoscopic and open gastric resections for malignant lesions: a prospective comparative study. Surg Endosc 19:933-938

22. Kawamura H, Yokota R, Homma S et al (2010) Comparison of respiratory function recovery in the early phase after laparoscopyassisted gastrectomy and open gastrectomy. Surg Endosc 24:2739-2742

23. Kim SG, Lee YJ, Ha WS et al (2008) LATG with extracorporeal esophagojejunostomy: is this minimally invasive surgery for gastric cancer? J Laparoendosc Adv Surg Tech A 18:572-578

24. Kim MG, Kim BS, Kim TH et al (2011) The effects of laparoscopic assisted total gastrectomy on surgical outcomes in the treatment of gastric cancer. J Korean Surg Soc 80:245-250

25. Mochiki E, Toyomasu Y, Ogata K et al (2008) Laparoscopically assisted total gastrectomy with lymph node dissection for upper and middle gastric cancer. Surg Endosc 22:1997-2002 
26. Sakuramoto S, Kikuchi S, Futawatari N et al (2009) Laparoscopy-assisted pancreas- and spleen-preserving total gastrectomy for gastric cancer as compared with open total gastrectomy. Surg Endosc 23:2416-2423

27. Siani LM, Ferranti F, De Carlo A et al (2012) Completely laparoscopic versus open total gastrectomy in stage I-III/C gastric cancer: safety, efficacy and five-year oncologic outcome. Minerva Chir 67:319-326

28. Usui S, Yoshida T, Ito K et al (2005) Laparoscopy-assisted total gastrectomy for early gastric cancer: comparison with conventional open total gastrectomy. Surg Laparosc Endosc Percutan Tech 15:309-314

29. Bo T, Peiwu Y, Feng Q et al (2013) Laparoscopy-assisted vs. open total gastrectomy for advanced gastric cancer: long-term outcomes and technical aspects of a case-control study. J Gastrointest Surg 17:1202-1208

30. Lee MS, Lee JH, Park do J et al (2013) Comparison of short- and long-term outcomes of laparoscopic-assisted total gastrectomy and open total gastrectomy in gastric cancer patients. Surg Endosc 27:2598-2605

31. Stroup DF, Berlin JA, Morton SC et al (2000) Meta-analysis of observational studies in epidemiology: a proposal for reporting. Meta-analysis Of Observational Studies in Epidemiology (MOOSE) group. JAMA 283:2008-2012
32. Jeong O, Ryu SY, Choi WY et al (2014) Risk factors and learning curve associated with postoperative morbidity of laparoscopic total gastrectomy for gastric carcinoma. Ann Surg Oncol 9:2994-3001

33. Kim BS, Kim MG, Kim KC et al (2011) A practical way to overcome the learning period of laparoscopic gastrectomy for gastric cancer. Surg Endosc 25:3838-3844

34. Ev Cutsem, Dicato M, Geva R et al (2010) (2011): The diagnosis and management of gastric cancer: expert discussion and recommendations from the 12th ESMO/World congress on gastrointestinal cancer, Barcelona. Ann Oncol 22:v1-v9

35. Dikken JL, Stiekema J, van de Velde CJH et al (2013) Quality of Care indicators for the surgical treatment of gastric cancer: a systematic review. Ann Surg Oncol 20:381-398

36. Kattan MW, Karpeh MS, Mazumdar M et al (2003) Postoperative nomogram for disease-specific survival after an R0 resection for gastric carcinoma. J Clin Oncol 21:3647-3650

37. Japanese Gastric Cancer Association (1998) Japanese classification of gastric carcinoma, 2nd English edition. Gastric Cancer $1: 10-24$

38. Straatman J, van der Wielen N, Cuesta MA et al (2015) Surgical techniques, open versus minimally invasive gastrectomy after chemotherapy (STOMACH trial): study protocol for a randomized controlled trial. Trials 16:123 